\title{
Diagnostic accuracy of saline infusion sonography as compared to hysteroscopy in premenopausal women with abnormal uterine bleeding
}

\author{
Manoj Kumar Tangri*, Ajay Krishna Srivastava
}

Department of Obstetrics and Gynecology, Command Hospital Eastern Command, Kolkata, West bengal, India

Received: 11 December 2016

Accepted: 05 January 2017

*Correspondence:

Dr. Manoj Kumar Tangri,

E-mail: mktangri@rediffmail.com

Copyright: $\odot$ the author(s), publisher and licensee Medip Academy. This is an open-access article distributed under the terms of the Creative Commons Attribution Non-Commercial License, which permits unrestricted non-commercial use, distribution, and reproduction in any medium, provided the original work is properly cited.

\begin{abstract}
Background: In patients with abnormal uterine bleeding (AUB), differentiating whether the cause is anovulation or anatomic lesions can be challenging. Transvaginal sonography (TVS) has limitation in form of high false negative rate for diagnosing focal intrauterine pathology. To improve the image in TVS, saline injected into uterine cavity can be used as a negative contrast agent. Aim of our study was to evaluate the clinical value of saline infusion sonography (SIS) by comparing its diagnostic accuracy with that of established gold standard i.e. hysteroscopy.

Methods: The study was carried out in a referral and teaching public sector hospital in eastern India from July 2015 to June 2016. Study population consisted of 136 premenopausal women with AUB, who were scheduled to undergo diagnostic hysteroscopy. Patients were first evaluated by sis and then followed by hysteroscopy on a later date.

Results: Both SIS and hysteroscopy could be successfully performed in 136 out of 144 patients. When all findings by SIS (any pathological findings in uterine cavity vs. none) were combined and compared with hysteroscopy (gold standard), both sensitivity and specificity of sis were 0.88 whereas PPV and NPV were 0.85 and 0.90 respectively.

Conclusions: Because of comparable results obtained by evaluating patients by SIS as well as office hysteroscopy, we recommend saline infusion sonography as a valuable tool for evaluating premenopausal women with abnormal uterine bleeding, before consideration for hysteroscopy.
\end{abstract}

Keywords: AUB, Hysteroscopy, NPV, PPV, SIS, TVS

\section{INTRODUCTION}

Though abnormal uterine bleeding (AUB) is a common clinical problem, it presents to the gynecologist as diagnostic dilemma. The causes of AUB are diverse, and differentiating whether the source is the result of anovulation or anatomic lesions, can be challenging. ${ }^{1}$

Most common modalities used to assess anatomic causes of AUB have been endometrial biopsy, curettage, transvaginal sonography (TVS) and hysteroscopy. Office endometrial sampling devices offered reduced expense, less anesthesia requirements, increased convenience and safety. ${ }^{2}$ However, such devices have shown to have severe short comings especially in cases where the abnormality is focal and not global. ${ }^{3,4}$
Hysteroscopy is accepted as the "Gold Standard" for the evaluation of uterine cavity. It allows direct visualization of uterine cavity, and abnormalities can be immediately biopsied. However, there are concerns that it is a costly invasive procedure associated with its share of discomfort and risks. It is even unnecessary in 50\% of patients who have normal uterine cavity. ${ }^{5}$

TVS, though an excellent method for imaging uterine and endometrial abnormalities, but it has limitation in form of high false negative rate for diagnosing focal intrauterine pathology. ${ }^{6,7}$ To improve the image in TVS, saline injected into uterine cavity can be used as a negative contrast agent. Saline injection also distends the uterine walls, thereby showing structural abnormalities of the endometrium. Saline infusion sonography (SIS) is a 
diagnostic technique with many advantages. It is performed comparatively in lesser time, is more cost effective and is less painful for patients than hysteroscopy. Moreover, only few gynecologists perform office hysteroscopy, whereas the USG performed either by gynecologist or radiologist in office setting is more widely available than hysteroscopy. Hence, SIS has the potential to become a practical tool in office gynecology in evaluation of abnormal uterine bleeding.

The aim of this study was to evaluate the clinical value of SIS by comparing its diagnostic accuracy with that of established gold standard i.e. hysteroscopy.

\section{METHODS}

The study was carried out in a referral and teaching public sector hospital in eastern India. Study population consisted of premenopausal women with AUB, who were scheduled to undergo diagnostic hysteroscopy. Study population was first evaluated by SIS and then followed by hysteroscopy on a later date.

Inclusion criteria for the study were premenopausal nonpregnant women with AUB and normal cervical cytology. Exclusion criteria were suspected pelvic inflammatory disease, active menstrual bleeding, and presence of adnexal masses, cervical pathology or known genital tract malignancy.

Examination was done after cessation of menses but before $10^{\text {th }}$ day of menstrual cycle. Procedure was explained to each patient and consent obtained. SIS and hysteroscopy were performed separately by two specialists on each patient, who recorded their results without knowledge of each other's findings. Same specialist performed the procedure throughout the study.

For saline infusion sonography, patient was put in dorsal lithotomy position. Conventional TVS, to obtain coronal and sagittal views of uterus and adnexa was performed. This was performed on Wipro GE Medical System USG machine with a $5.0 \mathrm{MHz}$ transvaginal probe. TVS probe was then removed and with aseptic precautions, anterior lip of cervix was held using Sims speculum and valsellum forceps. A sterile disposable balloon catheter (size Ch 08) was introduced into cervical orifice until it reached the fundus. The speculum was then withdrawn and TVS probe introduced. $50 \mathrm{ml}$ sterile syringe was attached to the catheter and slow infusion of $20-25 \mathrm{ml}$ saline was done until the intrauterine cavity was clearly observed. Uterine cavity was then evaluated in coronal and sagittal views. . With the use of SIS, the diagnosis was made on the basis of the criteria described by Parsons and Lense ${ }^{8}$, findings were defined as normal cavity (smooth endometrium with the same thickness throughout the cavity and sharp border to the myometrium and the cavity), endometrial polyp (smooth margined, echogenic mass, emerging from the endometrium and does not disrupt the myometrial - endometrial interface), submucous myoma (solid, round structure of mixed echogenicity, emanating from the myometrium), hyperplasia (diffusely and irregularly thickened endometrium with an intact endometrialmyometrial interface). whenever any lesion was detected, operative hysteroscopic procedure was done as deemed necessary.

No antibiotic prophylaxis was given. Analgesics were given as on required basis. Patients were advised to review back if: Temperature $>100^{\circ} \mathrm{F}$, Foul smelling discharge or abnormal bleeding per vaginum, persistent pelvic/abdominal pain, after the procedure. Hysteroscopy was performed in operation theatre under general anesthesia using $5 \mathrm{~mm}$ rigid 30 degree hysteroscope. Distension medium used was normal saline. The hysteroscope was advanced under direct visualization into the uterus. The masses found were characterized, measured and recorded on a separate data sheet.

\section{RESULTS}

The study was carried out from July 2015 to June 2016. A total of 144 patients consented and were enrolled for the study. In 8 patients $(5.55 \%)$ either or both procedures could not be performed because of various reasons. In 2 patients $(1.38 \%)$ SIS could not be performed because of cervical stenosis.

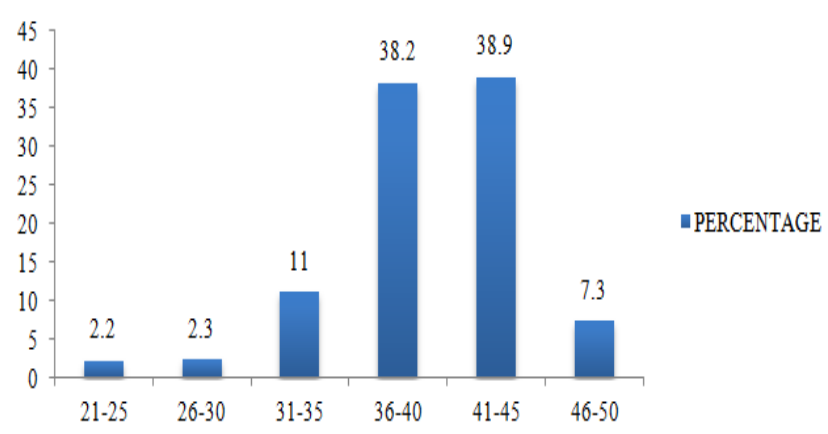

Figure 1: Age groups (years).

Four patients $(2.77 \%)$ underwent SIS but did not report for hysteroscopy. In two patients $(1.38 \%)$ SIS could not be successfully performed due to poor visualization due to failure of distension of uterine cavity. On hysteroscopy, these patients were found to have dense synechiae (Asherman's). These eight patients hence, were not included in the analysis. The age distribution of the patients is shown in Figure 1. Abnormal uterine bleeding was commonest in the age group 41-45 years (38.9\%); followed closely by the age group between $36-40$ years $(38.2 \%)$. The mean age was 39.44 years (25-51years).

\section{Nature of menstrual disorders}

Patients presented with different forms of AUB. The duration of symptoms were ranging from three months to one year. Various symptoms presented and their 
percentages are depicted in Figure 2. In our study, menorrhagia $(58.8 \%)$ was the most common symptom.

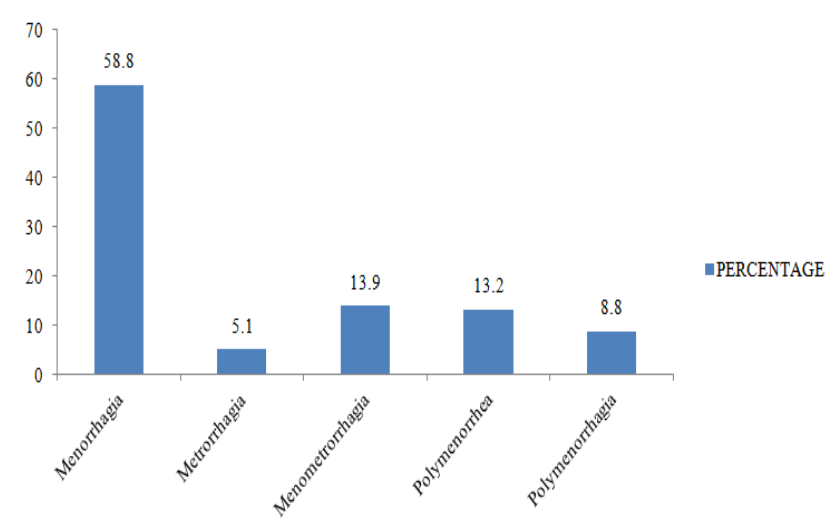

Figure 2: Symptoms.

Total no. of uterine cavity abnormalities, alone or in combination with other lesions as detected by SIS and hysteroscopy (gold standard) are shown in Figure 3.

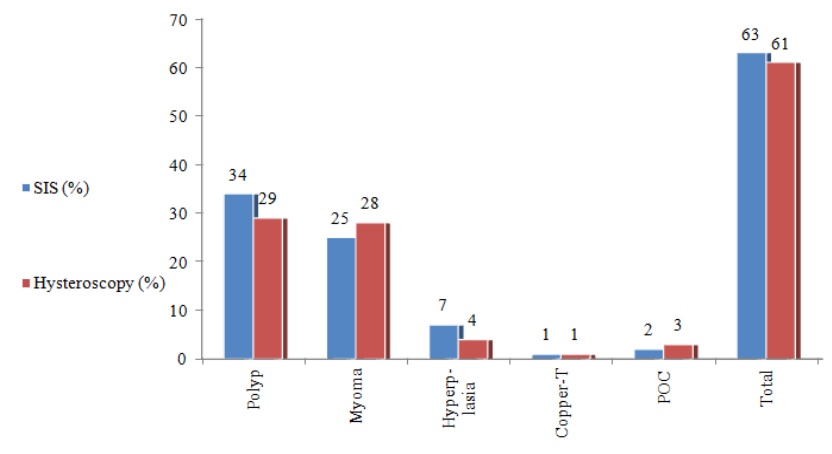

Figure 3: Uterine cavity abnormalities detected by SIS and hysteroscopy.
This data was used to construct $2 \times 2$ tables for calculating sensitivity, specificity, positive predictive value (PPV) and negative predictive value (NPV) of SIS in diagnosing various uterine cavity lesions. When all findings (any pathological findings Vs none) were combined, both sensitivity and specificity of SIS were 0.88 whereas PPV and NPV were 0.85 and 0.90 respectively (Table 2 ).

\section{SIS versus hysteroscopy}

Both procedures were performed in 136 patients with AUB. Hysteroscopy identified 75 normal uterine cavities $(55.1 \%)$ and 61 patients $(44.85 \%)$ were detected to have abnormalities. The results obtained by SIS were compared with those found on hysteroscopy (Table 1).

Table 1: Uterine cavity evaluation by SIS and hysteroscopy.

\begin{tabular}{|lll|}
\hline Lesions & SIS & Hysteroscopy \\
\hline Polyp & 30 & 26 \\
\hline Polyp + Myoma & 04 & 03 \\
\hline Myoma & 19 & 24 \\
\hline Myoma + Hyperplasia & 02 & 01 \\
\hline Hyperplasia & 05 & 03 \\
\hline Cu T & 01 & 01 \\
\hline Products of conception & 02 & 03 \\
\hline $\begin{array}{l}\text { No of uterine cavities } \\
\text { with lesions (Total of } \\
\text { above ser no 1-7) }\end{array}$ & 63 & 61 \\
\hline Normal cavity & 73 & 75 \\
\hline $\begin{array}{l}\text { Total no of patients } \\
\text { (II +III) }\end{array}$ & 136 & 136 \\
\hline
\end{tabular}

Table 2: Diagnostic potential of SIS with hysteroscopy as gold standard.

\begin{tabular}{|lllllll|}
\hline & Polyp & Myoma & Hyperplasia & Copper-T & POC & All intracavitory lesions \\
\hline Sensitivity & 0.79 & 0.85 & 1.0 & 1 & 0.66 & 0.89 \\
\hline Specificity & 0.89 & 0.99 & 0.97 & 1 & 1 & 0.89 \\
\hline $\begin{array}{l}\text { Positive Predictive } \\
\text { Value (PPV) }\end{array}$ & 0.67 & 0.96 & 0.57 & 1 & 1 & 0.87 \\
\hline $\begin{array}{l}\text { Negative Predictive } \\
\text { Value (NPV) }\end{array}$ & 0.94 & 0.96 & 1.0 & 1 & 0.99 & 0.90 \\
\hline
\end{tabular}

Figure-3 compares the number of various uterine lesions as detected by both SIS and hysteroscopy. SIS detected 30 patients with intrauterine polyps, submucous myoma in 19 patients, endometrial hyperplasia in 5 patients, polyps were diagnosed co-existing with myoma in 4 patients and 2 patients had myoma co-existing with endometrial hyperplasia. Intrauterine device (Copper-T) was found in 01 and products of conception (POC) were diagnosed in 2 patients.

Whereas hysteroscopy detected 26 patients with intrauterine polyps, submucous myoma in 24 patients, endometrial hyperplasia in 3 patients, polyps were diagnosed co-existing with myoma in 3 patients. One patient had myoma with coexisting endometrial 
hyperplasia. Intrauterine device and POC were diagnosed in 01 and 03 patients respectively. Average time taken for SIS was 6.3 minutes from insertion of catheter to completion of the procedure.

In present study while performing SIS, we could detect eleven patients with intramural fibroids; five had ovarian cysts and two patients had adnexal mass (Figure 4). No infection or complication occurred during the study while performing SIS or hysteroscopy.

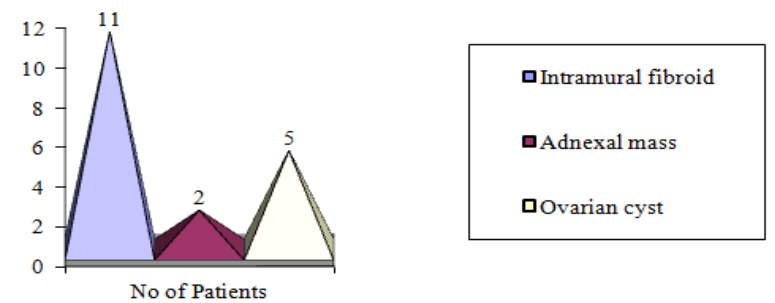

Figure 4: Evaluation beyond endometrium.

Table 3: Incidence of uterine cavity abnormalities.

\begin{tabular}{|c|c|c|c|c|c|c|}
\hline Study & $\begin{array}{l}\text { Normal cavity } \\
(\%)\end{array}$ & $\begin{array}{l}\text { Polyp } \\
(\%)\end{array}$ & $\begin{array}{l}\text { Myoma } \\
(\%)\end{array}$ & $\begin{array}{l}\text { Polyp and } \\
\text { myoma }(\%)\end{array}$ & $\begin{array}{l}\text { Hyperplasia } \\
(\%)\end{array}$ & Other lesions \\
\hline $\begin{array}{l}\text { Widrich et al } \\
\mathrm{N}=113^{11}\end{array}$ & 49.4 & 21.2 & 18.6 & 3.5 & 2.7 & $\begin{array}{l}\text { Endometrial } \\
\text { cancer- } 0.9 \%, \\
\text { Synechiae- } 2.7 \%\end{array}$ \\
\hline $\begin{array}{l}\text { Indman } \\
\mathrm{N}=234^{9}\end{array}$ & 41 & 20 & 31 & 3 & 2 & $\begin{array}{l}\text { Endometrial cancer } \\
1 \% \text {, others } 2 \%\end{array}$ \\
\hline $\begin{array}{l}\text { Towbin } \\
\mathrm{N}=149^{12}\end{array}$ & 24 & 22 & 33 & 5 & 4 & $\begin{array}{l}\text { Adenomyosis } \\
11 \% \text {, others } 1 \%\end{array}$ \\
\hline $\begin{array}{l}\text { Rudra }^{13} \\
N=200\end{array}$ & 56 & 14 & 24.5 & 1 & 1.5 & $\begin{array}{l}\text { Synechiae- } 2.7 \% \text {, } \\
\text { POC-3\% }\end{array}$ \\
\hline $\begin{array}{l}\text { Present study } \\
(\mathrm{N}=136)\end{array}$ & 55.14 & 19.1 & 17.6 & 2.2 & 2.2 & $\begin{array}{l}\mathrm{Cu}-\mathrm{T} 0.7 \%, \mathrm{POC} \\
2.2 \% \text {, Myoma and } \\
\text { Hyperplasia- } 0.7 \%\end{array}$ \\
\hline
\end{tabular}

Table 4: Studies reporting diagnostic accuracy of SIS for endometrial abnormalities.

\begin{tabular}{|c|c|c|c|c|c|c|c|}
\hline \multirow[b]{2}{*}{$\begin{array}{l}\text { First } \\
\text { author }\end{array}$} & \multirow[b]{2}{*}{ Year } & \multirow[b]{2}{*}{ No. patients (status) } & \multirow[b]{2}{*}{ Reference test } & \multicolumn{4}{|l|}{ SIS } \\
\hline & & & & $\begin{array}{l}\text { Sensitivity } \\
(\%)\end{array}$ & $\begin{array}{l}\text { Specificity } \\
(\%)\end{array}$ & $\begin{array}{l}\text { PPV } \\
(\%)\end{array}$ & $\begin{array}{l}\text { NPV } \\
(\%)\end{array}$ \\
\hline Widrich $^{11}$ & 1996 & $\begin{array}{l}113 \text { (Pre and } \\
\text { Postmenopausal) }\end{array}$ & Hysteroscopy & 96 & 88 & 89 & 96 \\
\hline Rudra $^{13}$ & 2009 & $\begin{array}{l}200 \text { (Pre and } \\
\text { Postmenopausal) }\end{array}$ & Hysteroscopy & 90 & 88 & 86 & 92 \\
\hline Kroon $^{16}$ & 2003 & $\begin{array}{l}877 \text { (Pooled homogenous } \\
\text { data from pre and post } \\
\text { menopausal) }\end{array}$ & $\begin{array}{l}\text { Hysterectomy } \\
\text { and/or } \\
\text { Hysteroscopy }\end{array}$ & $\begin{array}{l}95 \\
\text { (CI } 93 \text { to } 97)\end{array}$ & $\begin{array}{l}88 \\
\text { (CI } 85 \text { to } 92)\end{array}$ & - & - \\
\hline Chawla $^{17}$ & 2014 & $\begin{array}{l}60 \text { (Pre and } \\
\text { Postmenopausal) }\end{array}$ & Hysteroscopy & 89 & 100 & 100 & 73 \\
\hline $\begin{array}{l}\text { Current } \\
\text { study }\end{array}$ & 2016 & 136 Premenopausal & Hysteroscopy & 88 & 88 & 85 & 90 \\
\hline
\end{tabular}

\section{DISCUSSION}

In our study, the age distribution was from 25 years to 51 years. Age group 36-45 years constituted $77.1 \%$ patients our study group. Maximum patients $(38.9 \%)$ were from age group 41-45 years. Indman $\mathrm{PD}^{9}$ in his study of abnormal uterine bleeding reported $43.2 \%$ patients from the age group 40-49 years. We found menorrhagia to be the commonest symptom $(58.8 \%$ of patients reported with AUB). Finikiotis $G$ also reported menorrhagia in $62 \%$ of the cases of AUB. ${ }^{10}$
Incidence of various uterine abnormalities reported in literature (Table 3), in patients with AUB has been in the range of $44 \%$ to $76 \%$. We found the incidence of uterine cavity abnormality to be $44.7 \%$ and we did not come across any patient with endometrial carcinoma or synaechiae. Many studies (Table 4) have been done using SIS to diagnose endometrial abnormalities and they have reported upon diagnostic accuracy of SIS compared with the gold standard of hysteroscopy or hysterectomy in prospective, blinded fashion. ${ }^{11,14,15}$ Present study determined both sensitivity and specificity to be 0.88 for 
SIS, when compared with hysteroscopy. For diagnosing endometrial polyps, our study revealed sensitivity of $79 \%$ and specificity to be $89 \%$. The PPV and NPV were $67 \%$ and $94 \%$ respectively. While evaluating submucous myomas, SIS showed sensitivity of $85 \%$ and specificity of $99 \%$. The PPV and NPV were both $96 \%$.

Table 5: Diagnostic accuracy of SIS for various endometrial pathologies.

\begin{tabular}{|c|c|c|c|c|c|c|}
\hline Pathology & & $\begin{array}{l}\text { Our study } \\
(\%)\end{array}$ & $\begin{array}{l}\text { Widrich et } \\
\mathrm{a}^{11}(\%)\end{array}$ & $\begin{array}{l}\text { Rudra et al }{ }^{13} \\
(\%)\end{array}$ & $\begin{array}{l}\text { Meta-analysis by } \\
\text { Kroon et } \mathbf{a l}^{16}(\%)\end{array}$ & $\begin{array}{l}\text { Nallapati et } \\
\mathrm{al}^{18}(\%)\end{array}$ \\
\hline \multirow{2}{*}{$\begin{array}{l}\text { Endometrial } \\
\text { polyp }\end{array}$} & Sensitivity & 79 & 87 & 93 & $\begin{array}{l}86 \% \\
(95 \% \text { CI } 81 \%- \\
91 \%)\end{array}$ & 90.9 \\
\hline & Specificity & 89 & 90 & 94.1 & $\begin{array}{l}81 \% \\
(95 \% \text { CI } 72 \%- \\
88 \%)\end{array}$ & 92.68 \\
\hline \multirow{2}{*}{$\begin{array}{l}\text { Submucosal } \\
\text { fibroid }\end{array}$} & Sensitivity & 85 & 93 & 88.2 & $\begin{array}{l}87 \% \\
(95 \% \text { CI } 79 \%- \\
92 \%)\end{array}$ & 86.36 \\
\hline & Specificity & 99 & 99 & 97.3 & $\begin{array}{l}92 \% \\
(95 \% \text { CI } 86 \%- \\
95 \%)\end{array}$ & 83 \\
\hline \multirow{2}{*}{$\begin{array}{l}\text { Endometrial } \\
\text { hyperplasia }\end{array}$} & Sensitivity & 100 & 100 & 100 & & 100 \\
\hline & Specificity & 97 & 95 & 97.9 & & 94 \\
\hline
\end{tabular}

Various studies (Table 5) have shown similar results in diagnosing polyps, submucous fiborids and hyperplasia. Widrich et $\mathrm{al}^{11}$ in his study found sensitivity of $87 \%$ and specificity of $90 \%$ for diagnosing polyp by SIS, where as for diagnosis of submucous fibroids, sensitivity and specificity were $93 \%$ and $99 \%$ respectively. He suggested that, distinguishing between large polyps and pedunculated myoma is difficult with either technique, since both these pathologic conditions can be treated with hysteroscopic resection; hence the treatment does not change even if lesions are confused with each other.

In the meta-analysis done by Kroon et $\mathrm{al}^{16}$, pooled sensitivity and pooled specificity of SIS for endometrial polyps was $86 \%(95 \%$ CI $81 \%-91 \%)$ and $81 \%$ (95\% CI $72 \%-88 \%$ ) respectively. For intrauterine fibroids pooled sensitivity and pooled specificity of SIS was $87 \%(95 \%$ CI 79\%-92\%) and $92 \%$ (95\% CI 86\%-95\%) respectively. For hyperplasia, sensitivity of SIS in our study was very high i.e. $100 \%$ and the specificity was $97 \%$. Various other studies of SIS also reported $100 \%$ sensitivity and 94\%-97.9\% specificity for hyperplasia (Table 5). In three patients having retained POC, SIS could diagnose correctly in two patients. Thus by SIS, sensitivity and specificity for products of conception was $66 \%$ and $100 \%$ respectively.

The average time for SIS was 6.3 minutes from insertion of catheter to completion of the procedure. During initial part of the study, time taken was comparatively longer, but as the expertise gained, the procedure could be completed in lesser and lesser time. Usually it took $<15$ minutes to complete transvaginal sonography and SIS.
Widrich et al $^{11}$ have reported an average time of 3.5 minutes in their study.

No infection or complication occurred during the study while performing SIS or hysteroscopy. There have been no published reports of uterine perforation with SIS. SIS decreases the need of expensive equipment for outpatient hysteroscopy and it may be helpful especially in hospitals where office hysteroscopy is not available. Moreover, it may be a valuable technique even when hysteroscopy is available, as an initial screening test to triage patients who may benefit from hysteroscopy. Chambers and Chambers $^{2}$ concluded that the expense and time involved in the use of hysteroscopy are not justified for routine evaluation of women with abnormal uterine bleeding. Williams and Marshburn ${ }^{19}$, in their study found that, if SIS had been used to triage their patients to determine whether hysteroscopy was indicated, 23 out of 39 women (59\%) would not have needed diagnostic (office) hysteroscopy. In present study, SIS could successfully rule out abnormality in $48.5 \%$ patients. The results were comparable with both diagnostic techniques i.e. SIS as well as office hysteroscopy. Hence, we too believe in the conclusion, as derived by Goldstein et $\mathrm{al}^{20}$ that, hysteroscopy with curettage should be reserved for those patients with demonstrated focal abnormality on SIS, who are in need of visually directed removal or whose ultrasonographic triage was unable to exclude significant abnormality.

\section{CONCLUSION}

PIH was the most common etiology of high risk pregnancy. Doppler velocimetry was better in predicting 
fetal compromise in comparison to NST in high risk pregnancies. Normal NST and normal Doppler velocimetry were not significantly different in prediction of fetal outcome. Abnormal Doppler value was better in predicting fetal compromise in comparison to abnormal NST. Cerebroplacental ratio was very accurate and was good predictor of adverse perinatal outcome. Both NST and Doppler velocimetry complemented each other in fetal surveillance of high risk pregnancy, although Doppler studies were more efficacious.

\section{Funding: No funding sources}

Conflict of interest: None declared

Ethical approval: The study was approved by the Institutional Ethics Committee of SMIMS

\section{REFERENCES}

1. William CD, Paul B. Marshburn. A prospective study of transvaginal hydrosonography in the evaluation abnormal uterine bleeding. Am J Obstet Gynecol. 1998;179:292-8.

2. Chambers J, Chambers S. Endometrial sampling: when? Where? Why? With what? Clin Obstet Gynaecol. 1992;35:28-39.

3. Dubinsky TJ, Parvey HR, Gormaz G. Transvaginal hysterosonography: Comparison with biopsy in the evaluation of postmenopausal bleeding. J Ultrasound Med. 1995;14:887-93.

4. Guido RS, Kanbour Shakir A, Rulin MC. Pipelle endometrial sampling: Sensitivity in the detection of endometrial lesions. Cancer Journal of Reproductive Medicine. 1995;40:553-5.

5. Angioni S, Loddo A, Milano F. Detection of intracavitary lesion in postmenopausal women with abnormal uterine bleeding:a prospective comparative study on outpatient hysteroscopy and blind biopsy. J Minim Invasive Gynecol. 2008;15:87-91.

6. Granberg S, Wikland M, Karlsson B. Endometrial thickness as measured by endovaginal ultrasonography for identifying endometrial abnormality. Am J Obstet Gynecol. 1991;64:47-52.

7. Debra L, Berridge, Thomas C. Saline infusion sonohysterography technique, indications, and imaging findings. J Ultrasound Med. 2004;23:97-112.

8. Parson AK, Lense H. Sonohysterography for endometrial abnormalities: preliminary results. J Clin Ultrasound. 1993;21:87-95.

9. Indman PD. Abnormal uterine bleeding: Accuracy of vaginal probe ultrasound in predicting abnormal hysteroscopic findings. J Reprod Med. 1995;40:545-8.
10. Finikiotis G. Hysteroscopy an analysis of 523 patients. Aust Nz J Obst Gyn. 1989;29:253-8.

11. Widrich T, Bradley LD, Mitchinson A. Comparison of saline infusion sonography with office hysteroscopy for the evaluation of the endometrium. Am J Obstet Gynecol. 1996;174:1327-34.

12. Towbin NA, Gviazda IM, March CM. Office hysteroscopy versus transvaginal sonography in the evaluation of patients with excessive uterine bleeding. Am J Obstet Gynecol. 1996;174:1678-82.

13. Rudra S, Duggal BS, Bharadwaj D. Prospective study of saline infusion sonography and office hysteroscopy. Med J Armed Forces India. 2009;65:332-5.

14. Cicinelli E, Romano F, Anastasio P. Transabdominal sonohysterography, transvaginal sonography, and hysteroscopy in the evaluation of submucous myomas. Obstet Gynecol. 1995; 85:42-7.

15. Wolman I, Jaffa AJ, Hartoov J, Amiram BA, David MP. Sensitivity and specificity of sonohysterography for the evaluation of the uterine cavity in perimenopausal patients. J Ultrasound Med. 1996; 15:285-8.

16. de Kroon CD, de Bock GH. Saline contrast hysterosonography in abnormal uterine bleeding: a systematic review and meta-analysis. BJOG: an International Journal of Obstetrics and Gynaecology. 2003;110:938-47.

17. Chawla I, Tripathi S, Vohra P, Singh P. To evaluate the accuracy of Saline Infusion Sonohysterography (SIS) for Evaluation of Uterine Cavity Abnormalities in Patients with Abnormal Uterine Bleeding. The Journal of Obstetrics and Gynecology of India. 2014;64(3):197201.

18. Sowjanya N, Pallavee P. Comparative study of saline infusion sonography and hysteroscopy for evaluation of uterine cavity in abnormal uterine bleeding. Int $\mathrm{J}$ Reprod Contracept Obstet Gynecol. 2015;4(3):828-32.

19. William CD, Paul B. A prospective study of transvaginal hydrosonography in the evaluation abnormal uterine bleeding. Am J Obstet Gynecol. 1998;179:292-8.

20. Goldstein SR, Zeltser I, Horan CK. Ultrasonography based triage for perimenopausal patients with abnormal uterine bleeding. Am J Obstet Gynecol. 1997;177:1028.

Cite this article as: Tangri MK, Srivastava AK.

Diagnostic accuracy of saline infusion sonography as compared to hysteroscopy in premenopausal women with abnormal uterine bleeding. Int J Reprod Contracept Obstet Gynecol 2017;6:682-7. 